\title{
Which doctors and with what problems contact a specialist service for doctors? A cross sectional investigation Antony I Garelick*1, Samantha R Gross' ${ }^{2}$, Irene Richardson ${ }^{3}$, Matthias von der Tann ${ }^{1}$, Julia Bland ${ }^{4}$ and Rob Hale ${ }^{1}$
}

\author{
Address: ${ }^{1}$ MedNet Service for Doctors, Tavistock \& Portman NHS Trust, 120 Belsize Lane, London NW3 5BA, UK., ${ }^{2}$ National Addiction Centre, \\ Institute of Psychiatry, King's College London, DeCrespigny Park, Denmark Hill, London SE5 8AF, UK., 3Tavistock \& Portman NHS Trust, 120 \\ Belsize Lane, London NW3 5BA, UK. and ${ }^{4}$ MedNet Service for Doctors, Maudsley Hospital, Denmark Hill, London SE5 8AZ, UK. \\ Email: Antony I Garelick* - AGarelick@tavi-port.nhs.uk; Samantha R Gross - s.gross@iop.kcl.ac.uk; Irene Richardson - irenerichardson@club- \\ internet.fr; Matthias von der Tann - MVonDerTann@tavi-port.nhs.uk; Julia Bland - Julia.Bland@slam.nhs.uk; Rob Hale - RHale@tavi- \\ port.nhs.uk \\ * Corresponding author
}

Published: 28 August 2007

BMC Medicine 2007, 5:26 doi:10.1186/1741-70/5-5-26
Received: 20 November 2006

Accepted: 28 August 2007

This article is available from: http://www.biomedcentral.com/174I-7015/5/26

(c) 2007 Garelick et al; licensee BioMed Central Ltd.

This is an Open Access article distributed under the terms of the Creative Commons Attribution License (http://creativecommons.org/licenses/by/2.0), which permits unrestricted use, distribution, and reproduction in any medium, provided the original work is properly cited.

\begin{abstract}
Background: In the United Kingdom, specialist treatment and intervention services for doctors are underdeveloped. The MedNet programme, created in 1997 and funded by the London Deanery, aims to fill this gap by providing a self-referral, face-to-face, psychotherapeutic assessment service for doctors in London and South-East England. MedNet was designed to be a low-threshold service, targeting doctors without formal psychiatric problems. The aim of this study was to delineate the characteristics of doctors utilising the service, to describe their psychological morbidity, and to determine if early intervention is achieved.

Methods: A cross-sectional study including all consecutive self-referred doctors ( $n=121,50 \%$ male) presenting in 2002-2004 was conducted. Measures included standardised and bespoke questionnaires both self-report and clinician completed. The multi-dimensional evaluation included: demographics, CORE (CORE-OM, COREWorkplace and CORE-A) an instrument designed to evaluate the psychological difficulties of patients referred to outpatient services, Brief Symptom Inventory to quantify caseness and formal psychiatric illness, and Maslach Burnout Inventory.

Results: The most prevalent presenting problems included depression, anxiety, interpersonal, self-esteem and work-related issues. However, only $9 \%$ of the cohort were identified as severely distressed psychiatrically using this measure. In approximately $50 \%$ of the sample, problems first presented in the preceding year. About $25 \%$ were on sick leave at the time of consultation, while $50 \%$ took little or no leave in the prior 12 months. A total of $42 \%$ were considered to be at some risk of suicide, with more than $25 \%$ considered to have a moderate to severe risk. There were no significant gender differences in type of morbidity, severity or days off sick.

Conclusion: Doctors displayed high levels of distress as reflected in the significant proportion of those who were at some risk of suicide; however, low rates of severe psychiatric illness were detected. These findings suggest that MedNet clients represent both ends of the spectrum of severity, enabling early clinical engagement for a significant proportion of cases that is of importance both in terms of personal health and protecting patient care, and providing a timely intervention for those who are at risk, a group for whom rapid intervention services are in need and an area that requires further investigation in the UK.
\end{abstract}




\section{Background}

The prevalence of psychological morbidity in practicing doctors has been estimated at $25 \%[1,2]$. As a professional group, doctors are highly stressed [3-5], which is a situation that has been progressively increasing over time [6], and may be more susceptible to depression $[7,8]$, burnout and anxiety; However, robust comparative research on this topic is limited [9]. Women doctors have consistently been shown to have a higher risk of suicide than their male counterparts, and their suicide rates may be higher than for the general population [10]. However, rates of attempted suicide may be lower for doctors overall compared to the general population $[11,12]$. Despite these factors, doctors are notoriously reluctant to use health services, often citing profound concerns about confidentiality and stigma [13-15].

In the UK, treatment services specifically targeted for doctors are underdeveloped and little is know about the doctors that attend these services [16] or the consequences of their problems on either personal health or clinical practice in the long-term. While doctors may access telephone counselling or mentoring through their employer, membership society and some of the Royal Colleges, these programmes do not offer face to face contact in a specialised designated clinic for doctors. This study, the first of its type, has investigated by direct clinical evaluation a cohort of doctors attending a specialist psychotherapeutic service for doctors in distress.

The aim of this study was to provide a comprehensive description of doctors seeking help at one service for psychological difficulties, based not only on standardised questionnaires, but also on clinical interviews and clinician ratings.

\section{Methods}

\section{The service}

MedNet was established in 1997 by the London Deanery, which is now responsible for all postgraduate education in the London area. The MedNet service also covers an area of southern England (Kent, Surrey and Sussex Deanery). It is a self-referral service available to all doctors, not only those in training. The Tavistock Clinic hosts the MedNet service in North London; in South London it is hosted at the Maudsley Hospital. The service is staffed by three Consultant Psychiatrists in Psychotherapy on a sessional basis and a full-time secretary, and offers confidential brief assessments and longer-term psychological support as required. The consultations take account of the practical and cultural aspects of medical practice in the UK and explore psychological health, work-life balance and career issues. The aim of the service is to provide a therapeutic opportunity for doctors to identify and clarify the nature of their problems and how they interact with their professional and personal lives.

\section{The sample}

All doctors who contacted the service between February 2002 and February 2004 were eligible for inclusion ( $\mathrm{n}=$ 123). Of these, $98.4 \%(\mathrm{n}=121)$ consented to take part. Complete data was obtained for 107 clients, and partial data was collected for 14 .

\section{Measures}

Data collection included standardised and bespoke questionnaires, utilising both self-report (prior to index appointment) and clinician-completed assessments (during index appointment). Bespoke questions included information on demographics, personal and family health history, education and professional training.

Information concerning levels of risk and the range, intensity and duration of problems was collected using the clinician-rated CORE Assessment (CORE-A) and the CORE Workplace Therapy Assessment Form (CORE-Workplace) [17]. Both of these tools provide for a broad picture of mental state and are not time limited.

Distress symptoms in the preceding week and standardised assessment of severity of presentation were captured by the CORE Outcome Measure (CORE-OM) and the Brief Symptom Inventory (BSI). The CORE-OM [18], which contains 34-items using a 5-point Likert response ('not at all' to 'most or all of the time'), provides scores for subjective wellbeing, commonly experienced problems or symptoms, life/social functioning and risk to self and others was also completed. Standardised scores were used to determine clinical cut points on this measure as provided by the distributor [18]. The Brief Symptom Inventory (BSI) [19], a 53-question, 5-point Likert scale (responses ranging from 'not at all' to 'extremely') self-rated questionnaire that targets symptoms in nine areas, was used to quantify 'caseness'. Caseness implies the criterion for requiring a formal mental health assessment and was computed using adult gender matched non-patient norms. Adult psychiatric outpatient norms for the BSI and the Global Severity Index (GSI) as a component of the BSI were used to measure clients' degree of symptomatic distress [19].

Work-related distress was evaluated through the three dimensions of the Maslach Burnout Inventory (MBI) [20]: 'emotional exhaustion', 'depersonalisation' and 'personal accomplishment', each of which is scored independently. The MBI is a 22-item questionnaire about job-related feelings, which uses a 7-point Likert scale to capture how often the individual has ever felt a certain way (responses 'never' to 'every day'). This questionnaire, like the CORE 
Workplace and CORE-A, is not as limited to point in time assessment.

\section{Data analysis}

Statistical analyses were conducted in SPSS v. 15 and included descriptives, Chi-Squared tests for categorical measures, t-tests or Mann-Whitney U test for skewed data, as well as Pearson's correlation coefficient to identify relationships between scale data.

\section{Results}

\section{Demographics}

An equal proportion of males $(n=61,50 \%)$ and females $(\mathrm{n}=60)$ presented to the service, with a mean age of $37 \pm$ 8.6 years (range $24-64$, Figure 1). The largest age group attending were $30-39$ years (47\%). There was no significant difference between the ages of male and female clients. The majority of clients were Caucasian ( $\mathrm{n}=79$, $65 \%)$, with the largest minority group Asian $(\mathrm{n}=24$, $20 \%)$. Most were married $(\mathrm{n}=68)$ and about $25 \%$ were single $(\mathrm{n}=33)$. Approximately $33 \%$ had children.

Clients represented a variety of career grades (Figure 2), with specialist registrars the largest group represented $(\mathrm{n}=$ $31)$ followed closely by senior house officers $(n=28)$. A total of 23 consultants attended, of which nine were in post $\leq 5$ years. There were no significant differences identified by gender and career grade. A total of $75 \%(n=89)$ stated that they had passed postgraduate exams, and 88 had completed a higher training. The specialties of psychiatry $(n=29)$ and medicine $(n=27)$ were the largest groups represented (Figure 3 ), followed closely by those specialising in general practice $(\mathrm{n}=21)$.

While all clients accessed the service via self-referral, 87 $(72 \%)$ indicated that they were encouraged to do so by at least one individual. Nine were referred by multiple parties. These included their GP $(\mathrm{n}=3)$, occupational health $(n=22)$, senior colleague (education) $(n=11)$, senior col-

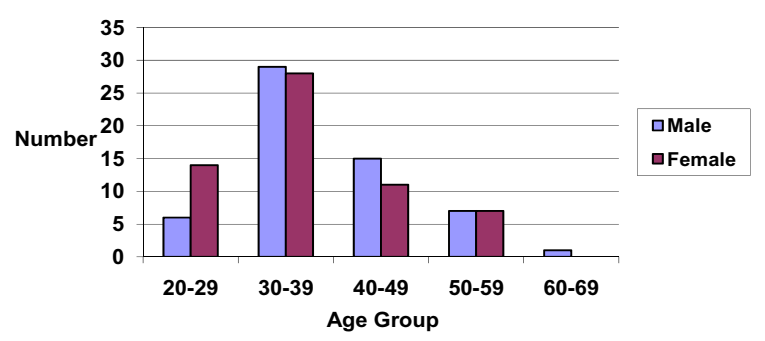

Figure I

Age distribution.

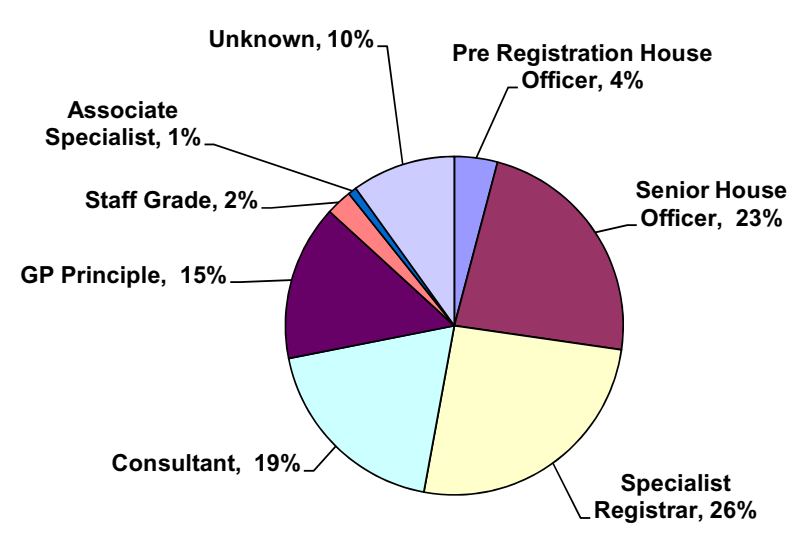

Figure 2

Training grade.

league (clinical) $(\mathrm{n}=27)$ and/or their postgraduate deanery $(\mathrm{n}=15)$, psychiatrist/psychologist/counsellor $(\mathrm{n}=$ $11)$, and a colleague, friend or partner $(n=7)$. For 10 clients referral route was not recorded. A total of 76 (63\%) respondents indicated that they had seen their GP in the past 12 months. Approximately 50\% $(n=58)$ had had a previous consultation with a psychiatrist.

\section{Presenting problems}

Data from clinician completed CORE-A (Table 1) indicated that the most prevalent presenting problems were depression, anxiety/stress, interpersonal problems, selfesteem problems, and work-related problems. These were coded as moderate or severe in the majority of cases and for a significant minority of doctors, these problems had appeared in the preceding year.

According to therapist rating on the CORE-A, $42 \%$ were considered to be at some risk of suicide, with more than $25 \%(n=12)$ considered to have a moderate to severe risk. A larger number of males $(n=27)$ than females $(n=19)$ were considered to be at risk, but this was not statistically significant. Eleven $(9.1 \%, 3$ male) clients had attempted suicide in the past, six on more than one occasion. In eight cases, an attempt had taken place in the 12 months preceding their contacting the service. Six of those who had attempted suicide in the past were considered to be at moderate to high suicidal risk at the time of presentation. None of those who had attempted suicide in the past were considered a risk for harm to others or a forensic risk.

Mean scores on the CORE-OM subscales at intake are detailed in Table 2. Clients scored worse than the general population but better than the clinical population (e.g. out-patients) on all sub-scales. Overall, $63 \%(n=72)$ of those who completed the assessment scored above clini- 


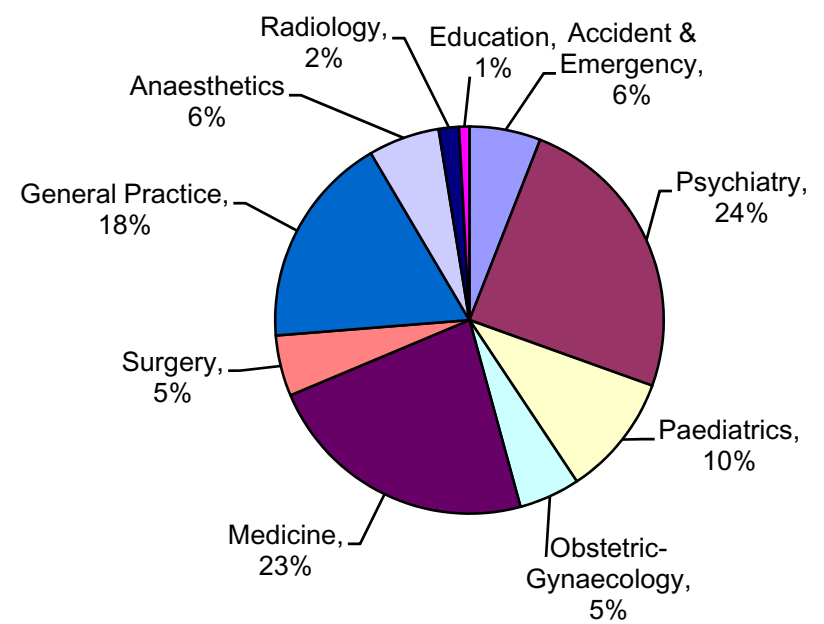

Figure 3

Medical speciality $(\mathrm{n}=\mathrm{I} \mid 2)$.

cal cut-off (1.19 for males, 1.29 for females) on their CORE-OM total score. A similar proportion of males $(61 \%)$ and females (64\%) reached clinical cut-off as did a similar proportion of junior (66\%) middle $(54.5 \%)$ and senior $(68.3 \%)$ grades. The only significant difference identified on the CORE-OM was that males had a lower score on the Wellbeing subscale than females $(\bar{X}=1.77$ vs $\overline{\mathrm{X}}=2.26$ respectively, $\mathrm{t}=-2.8, \mathrm{p}<0.01)$.

The BSI ( $\mathrm{n}=114$, Table 3$)$ was used to assess clinical severity of presentation. Caseness was computed using two different methods. The first, by scoring over clinical cut-off on two or more sub-scales (a t-score of $\leq 63)(n=93)$ and the second by scoring over clinical cut-off on the Global Severity Index $(\mathrm{n}=87)$. When $\mathrm{t}$-score was based on general population norms, $85.1 \%(n=97)$ of clients could be defined as potential psychiatric cases (i.e. individuals requiring formal mental health assessment) by either of these methods. However, when t-score was calculated based on adult outpatient psychiatric norms, only $9 \%$ (n $=11$ of 114) scored above cut-off, indicating that only a small proportion were severely psychiatrically distressed.

On the MBI ( $\mathrm{n}=114$, Table 2$)$, about $66 \%$ of clients presented with high levels of emotional exhaustion (score $\leq$ 27 ), 39\% (score $\leq 10$ ) with a high level of depersonalisation, and $40 \%$ (score $\geq 33$ ) were classified with a low level of personal accomplishment. Males had significantly higher scores on the personal accomplishment construct than females ( $\bar{X}=36$ vs $\bar{X}=32.7, t=2.2, p<0.05)$, however there was no significant difference between genders on reaching cut-off for burnout on this domain. Using the

Table I: CORE-A, presenting problems rated by therapist

\begin{tabular}{|c|c|c|c|c|c|c|c|}
\hline \multirow[t]{2}{*}{$\begin{array}{l}\text { Presenting } \\
\text { Problems }\end{array}$} & \multirow[t]{2}{*}{$\mathbf{N}$} & \multicolumn{2}{|c|}{ With problem } & \multicolumn{2}{|c|}{$\begin{array}{l}\text { Problem rated as moderate } \\
\text { or severe }\end{array}$} & \multicolumn{2}{|c|}{$\begin{array}{l}\text { Problem arisen in past } 12 \\
\text { months }\end{array}$} \\
\hline & & $\%$ & $\mathbf{n}$ & $\mathbf{n}$ & $\%$ & $\mathbf{n}$ & $\%$ \\
\hline Depression & 112 & 81.3 & 91 & 56 & 61.5 & 46 & 50.5 \\
\hline Anxiety & 110 & 58.2 & 64 & 43 & 67.2 & 31 & 48.4 \\
\hline Interpersonal & 111 & 45.9 & 51 & 32 & 62.7 & 11 & 21.6 \\
\hline Self esteem & 112 & 38.4 & 43 & 24 & 55.8 & 14 & 32.6 \\
\hline Work/academic & 111 & 32.4 & 36 & 21 & 58.3 & 16 & 44.4 \\
\hline Personality & 111 & 24.3 & 27 & 10 & 37 & 0 & 37 \\
\hline Bereavement & 111 & 15.3 & 17 & 11 & 64.7 & 8 & 47.1 \\
\hline Trauma & 112 & 9.8 & 11 & 9 & 81.8 & 4 & 36.4 \\
\hline Addictions & 112 & 5.4 & 6 & 3 & 50 & I & 16.7 \\
\hline Living/welfare & 112 & 3.6 & 4 & 4 & 100 & 3 & 75 \\
\hline Psychosis & 112 & 2.7 & 3 & 1 & 33.3 & 0 & 0 \\
\hline Physical & 112 & 2.7 & 3 & 2 & 66.7 & I & 33.3 \\
\hline Other: sexual & 112 & 2.7 & 3 & I & 33.3 & - & - \\
\hline $\begin{array}{l}\text { Cognitive/ } \\
\text { learning }\end{array}$ & 112 & 0.9 & 1 & 0 & 0 & 1 & 100 \\
\hline Eating disorder & 112 & 0.9 & 1 & 1 & 100 & 1 & 100 \\
\hline Risk: suicide & 110 & 41.8 & 46 & 12 & 26.1 & - & - \\
\hline Risk: self harm & 110 & 22.7 & 25 & 8 & 32 & - & - \\
\hline $\begin{array}{l}\text { Risk: harm to } \\
\text { others }\end{array}$ & 110 & 7.3 & 8 & 1 & 12.5 & - & - \\
\hline $\begin{array}{l}\text { Risk: forensic/ } \\
\text { legal }\end{array}$ & 110 & 0.9 & 1 & 0 & 0 & - & - \\
\hline
\end{tabular}


Table 2: Scores on CORE-OM $(n=I \mid 5)$ and MBI $(n=I \mid 4)$ at intake

\begin{tabular}{|c|c|c|c|c|c|c|c|c|}
\hline \multirow[t]{2}{*}{ Measure } & \multirow[t]{2}{*}{ Sub-scale } & \multirow[t]{2}{*}{ Score range } & \multicolumn{2}{|c|}{$\begin{array}{l}\text { Pre- } \\
\text { intervention }\end{array}$} & \multicolumn{2}{|c|}{ Above clinical cut-off } & \multicolumn{2}{|c|}{$\begin{array}{l}\text { Published } \\
\text { norms* }\end{array}$} \\
\hline & & & Mean & (SD) & $\mathbf{n}$ & (\%) & Mean & (SD) \\
\hline \multirow[t]{5}{*}{ CORE-OM } & Functioning & $0-3.75$ & $\mathrm{I} .4 \mathrm{I}$ & 0.76 & - & - & 0.85 & 0.65 \\
\hline & Problems & $0-3.92$ & 1.84 & 0.86 & - & - & 0.90 & 0.72 \\
\hline & Wellbeing & $0-4.00$ & 2.02 & 0.97 & - & - & 0.91 & 0.83 \\
\hline & Risk & $0-3.00$ & 0.32 & 0.48 & - & - & 0.20 & 0.45 \\
\hline & Total score & $0-3.68$ & 1.44 & 0.69 & 72 & 62.6 & 0.76 & 0.59 \\
\hline \multirow[t]{4}{*}{$\mathrm{MBI}$} & $\begin{array}{l}\text { Emotional } \\
\text { exhaustion }\end{array}$ & Jan-54 & 31.05 & 12.5 & 73 & 64 & 22.19 & 9.53 \\
\hline & $\begin{array}{l}\text { Depersonalisa } \\
\text { tion }\end{array}$ & $0-30$ & 8.8 & 6.95 & 44 & 38.6 & 7.12 & 5.22 \\
\hline & $\begin{array}{l}\text { Personal } \\
\text { accomplishme } \\
\text { nt }\end{array}$ & Feb-46 & 34.32 & 8.09 & 45 & 39.5 & 36.53 & 7.34 \\
\hline & Burnout** & - & - & - & 21 & 18.4 & - & - \\
\hline
\end{tabular}

*Normative data adapted from [17] (norms for non-clinical sample) and [20] (norms for sample in medicine); **high emotional exhaustion, depersonalisation and low personal achievement.

traditional method for interpretation of this scale, where 'burnout' equals high depersonalisation and emotional exhaustion and low personal achievement, 21 clients $(18.4 \%)$ reached this threshold. If one were to exclude the personal achievement construct, as recent authors have performed based on its' independence [8], the proportion of clients reaching classification of burnout increases to approximately $33 \%(n=36)$.

\section{Work-related difficulties}

More than $25 \%$ of clients $(n=31)$ had not taken any sick leave during the year prior accessing the service (11 did not respond). Of the 79 clients who had been on sick leave $(\bar{X}=46 \pm 74$ days, median $=14), 31(41 \%)$ had been on sick leave for a maximum of 7 days. In contrast, 34 clients had been on sick leave between 21 days (more than 1 working month) and 1 year $(\overline{\mathrm{X}}=98.32 \pm 88.7$ days, median $=65$ ). Where recorded, reasons for prolonged sick leave included psychological problems $(\mathrm{n}=$ 19 , primarily depression), both psychological and physical problems $(n=6)$, and physical problems only $(n=9$, including cold/virus, asthma and surgery), four of whom required hospitalisation. There were no significant differences in number of sick days by gender or by career grade.

More than $75 \%$ of clients $(\mathrm{n}=95)$ were dealing with work-related difficulties at the time of presentation, however only 36 clients were identified to have work issues as one of their primary presenting problems. Work issues were coded moderate or severe in 50 to $85 \%$ of cases, the majority appearing in the 12 months prior to the assess- ment (Table 4). Work functioning was considered by therapists normal or satisfactory in $55 \%(n=59)$ of clients, impaired or severely impaired in $15 \%(n=16)$. A total of $27 \%(n=29)$ were on sick leave at the time of assessment. Four of those whose work functioning was impaired $(\mathrm{n}=$ $13)$ and all of those with severe impairment $(n=3)$ had been on sick leave in excess of 20 days in the preceding year. There were no significant differences identified by gender and work-related difficulties. Many $(54 \%, \mathrm{n}=65)$ had work-related difficulties spanning multiple domains. Eight had or were presently undergoing formal proceedings at work ( 7 male), and two were suspended for clinical performance issues.

Days of sickness absence taken in the preceding year were significantly correlated with scores on each of the standardised psychological assessments used and the majority of their subscales, excluding anxiety and hostility on the BSI, problems and wellbeing on the CORE-OM and depersonalisation on the MBI. In addition, a larger proportion of those who had taken $\leq 21$ days sickness absence in the preceding year $(\mathrm{n}=34)$ met the classification for burnout on the MBI $\left(\chi^{2}=5.1, \mathrm{p}<0.05\right)$, or scored higher than normal population on the BSI $\left(\chi^{2}=4.82\right.$, $\mathrm{p}<$ 0.05 ) but there was no significant relationship between reaching clinical cut-off on the CORE-OM or the BSI for adult psychiatric outpatient norms and taking $\leq 21$ days sick leave. Doctors who had taken extended leave were rated with consistently higher mean workplace problem severity than those who had taken less or no time off, however this difference was only significant for the therapist rating of workload problems $(\overline{\mathrm{X}}=3.6$ vs $\overline{\mathrm{X}}=2.8, \mathrm{t}=$ 
Table 3: Raw scores on the BSI at intake and comparisons with normative data $(n=1 \mid 4)$

\begin{tabular}{|c|c|c|c|c|c|c|c|c|c|c|c|c|}
\hline \multirow[t]{2}{*}{ Measure } & \multirow[t]{2}{*}{ Sub-scale } & \multirow[t]{2}{*}{ Range } & \multicolumn{2}{|c|}{$\begin{array}{l}\text { MedNe } \\
\text { t pre- } \\
\text { interve } \\
\text { ntion }\end{array}$} & \multicolumn{2}{|c|}{$\begin{array}{l}\text { Adult non-patient } \\
\text { population published } \\
\text { norms (US)* }\end{array}$} & \multicolumn{2}{|c|}{$\begin{array}{l}\text { Adult psychiatric } \\
\text { outpatient } \\
\text { population published } \\
\text { norms (US)^ }\end{array}$} & \multicolumn{2}{|c|}{$\begin{array}{l}\text { Above clinical cut- } \\
\text { off: non-patient }\end{array}$} & \multicolumn{2}{|c|}{$\begin{array}{l}\text { Above clinical cut } \\
\text { off: psychiatric } \\
\text { outpatient }\end{array}$} \\
\hline & & & Mean & (SD) & Mean & (SD) & Mean & (SD) & $\mathbf{n}$ & (\%) & $\mathbf{n}$ & (\%) \\
\hline \multirow[t]{12}{*}{ BSI } & $\begin{array}{l}\text { Somatizatio } \\
\mathrm{n}\end{array}$ & $0-3.57$ & 0.44 & 0.62 & 0.29 & 0.40 & 0.83 & 0.79 & 20 & 17.5 & 5 & 4.4 \\
\hline & $\begin{array}{l}\text { Obsessive- } \\
\text { compulsive }\end{array}$ & $0-4$ & 1.42 & 0.95 & 0.43 & 0.48 & 1.57 & 1.00 & 71 & 62.3 & 9 & 7.9 \\
\hline & $\begin{array}{l}\text { Interperson } \\
\text { al sensitivity }\end{array}$ & $0-4$ & 1.36 & 1.01 & 0.32 & 0.48 & 1.58 & 1.05 & 73 & 64.0 & 8 & 7 \\
\hline & Depression & $0-4$ & 1.48 & 0.98 & 0.28 & 0.46 & 1.80 & 1.08 & 76 & 66.7 & 6 & 5.3 \\
\hline & Anxiety & $0-4$ & 1.13 & 0.94 & 0.35 & 0.45 & 1.70 & 1.00 & 54 & 47.4 & 5 & 4.4 \\
\hline & Hostility & $0-3.6$ & 0.74 & 0.75 & 0.35 & 0.42 & 1.16 & 0.93 & 35 & 30.7 & 6 & 5.3 \\
\hline & $\begin{array}{l}\text { Phobic } \\
\text { anxiety }\end{array}$ & $0-3.8$ & 0.45 & 0.74 & 0.17 & 0.36 & 0.86 & 0.88 & 33 & 28.9 & 7 & 6.1 \\
\hline & $\begin{array}{l}\text { Paranoid } \\
\text { ideation }\end{array}$ & $0-3.4$ & 0.92 & 0.86 & 0.34 & 0.45 & 1.14 & 0.95 & 49 & 43.0 & 7 & 6.1 \\
\hline & $\begin{array}{l}\text { Psychoticis } \\
\mathrm{m}\end{array}$ & $0-3$ & 0.81 & 0.67 & 0.15 & 0.30 & 1.19 & 0.87 & 70 & 61.4 & 4 & 3.5 \\
\hline & $\begin{array}{l}\text { Global } \\
\text { Severity } \\
\text { index }\end{array}$ & $0-3.51$ & 0.98 & 0.65 & 0.30 & 0.31 & 1.32 & 0.72 & 87 & 71.9 & 5 & 4.4 \\
\hline & $\begin{array}{l}\text { Positive } \\
\text { Symptom } \\
\text { Distress } \\
\text { index }\end{array}$ & $0-3.58$ & 26.33 & 10.53 & 11.45 & 9.20 & 30.80 & 11.63 & - & - & - & - \\
\hline & $\begin{array}{l}\text { Positive } \\
\text { Symptom } \\
\text { total }\end{array}$ & $0-53$ & 1.83 & 0.57 & 1.29 & 0.40 & 2.14 & 0.61 & - & - & - & - \\
\hline
\end{tabular}

* From [19].

$-3.4, \mathrm{p}=0.001)$. About $33 \%$ of those who reached classification for burnout were also classified with difficulties associated with job change on the CORE-Workplace $(\mathrm{n}=$ $\left.7, \chi^{2}=3.8, \mathrm{p}=0.05\right)$; there were no other significant relationships between these measures.

\section{Group at risk}

Of the 11 cases that had attempted suicide in the past, eight scored above clinical cut-off on the CORE-OM, two were classified with burnout according to the MBI, one who was off work for the entirety of the preceding year and the other took less than 20 days off. All were cases according to the BSI and two scored above adult psychiatric outpatient norms. This group had a higher number of sick days in the preceding year $(\overline{\mathrm{X}}=115$ vs $\overline{\mathrm{X}}=55, \mathrm{z}=$ $3.27, \mathrm{p}<0.001$ ) although three had taken less than 1 month leave. Nine of this group had previously consulted a psychiatrist. Similarly, of the 12 who were classed with moderate or severe suicidal risk at the time of presentation, two scored above outpatient psychiatric norms (one had attempted suicide in the past), and three had taken negligible time off sick.

Clients with any degree of risk for suicide, self-harm, harm to others and forensic/legal harm by therapists on the CORE-A had significantly higher scores on the CORE-OM risk subscale $(\overline{\mathrm{X}}=0.44$ vs $\overline{\mathrm{X}}=0.2 ; \mathrm{t}=-2.7, \mathrm{p}<0.01)$, but remained below the published clinical sample mean of 0.63 [18]. This group also had a higher number of days off sick in the preceding year $(\bar{X}=43$ vs $\bar{X}=58, z=2.6, p=$ $0.01)$.

Clients who were classified severely distressed on the BSI had significantly higher scores on the CORE-OM total score ( $\overline{\mathrm{X}}=2.4$ vs $\overline{\mathrm{X}}=1.4, \mathrm{t}=-5.36, \mathrm{p}<0.001)$ and on all subscales including depression, and on the MBI had a significantly higher score on the emotional exhaustion subscale $(\mathrm{t}=2.07, \mathrm{p}<0.05)$ and a lower score on the personal accomplishment subscale $(\mathrm{t}=4.04, \mathrm{p}<0.001)$. While they also had a significantly higher number of days off sick ( $\mathrm{z}$ $=2.4, \mathrm{p}<0.05)$, two had taken negligible time off, with a further two taking less than 1 month off.

\section{Discussion}

MedNet was established in order to assist doctors with problems who had hitherto not sought formal help. This service was thus not designed primarily for those known to established psychiatric illness. It was assumed that those with established psychological difficulties/psychiatric illness would already be in treatment (this includes doctors with substance misuse). 
Table 4: CORE-WORKPLACE therapist assessment, $n=108$

\begin{tabular}{|c|c|c|c|c|c|c|}
\hline \multirow[t]{2}{*}{ Domain } & \multicolumn{2}{|c|}{ With problem } & \multicolumn{2}{|c|}{ Moderate/severe } & \multicolumn{2}{|c|}{$\begin{array}{l}\text { Problem appeared in last } 12 \\
\text { months, }\end{array}$} \\
\hline & $\mathbf{n}$ & (\%) & $\mathbf{n}$ & (\%) & $\mathbf{n}$ & (\%) \\
\hline Change of job & 29 & 26.9 & 21 & 72.4 & 23 & 79.3 \\
\hline Workload & 48 & 44.4 & 37 & 77.1 & 19 & 39.6 \\
\hline Work conditions & 20 & 18.5 & 17 & 85 & 12 & 60 \\
\hline $\begin{array}{l}\text { Work } \\
\text { relationships }\end{array}$ & 32 & 29.6 & 22 & 68.8 & 12 & 37.5 \\
\hline Bullying & 12 & II.I & 6 & 50 & 7 & 58.3 \\
\hline Traumatic event & 5 & 4.6 & 4 & 80 & 5 & 100 \\
\hline Violence & I & 0.9 & I & 100 & I & 100 \\
\hline $\begin{array}{l}\text { Work-related } \\
\text { health }\end{array}$ & 10 & 9.3 & 7 & 70 & 6 & 60 \\
\hline Career issues & 29 & 26.9 & 16 & 55.2 & 12 & 41.4 \\
\hline $\begin{array}{l}\text { Organisational } \\
\text { issues }\end{array}$ & 8 & 7.4 & 6 & 75 & 4 & 50 \\
\hline $\begin{array}{l}\text { Formal } \\
\text { proceedings }\end{array}$ & 8 & 7.4 & 5 & 62.5 & 6 & 75 \\
\hline Other & 16 & 14.8 & 12 & 75 & 14 & 87.5 \\
\hline
\end{tabular}

The strength of this study is that it describes in detail for the first time an under-researched group in the actual clinical setting. Furthermore, a strict assessment protocol was adhered to, involving the use of reliable and valid psychometric instruments. Nevertheless, the study presents a number of limitations in so far as it has no control group and clients referred themselves to the service (although they were often strongly encouraged to do so).

An almost equal number of male and female doctors referred themselves, and there was no difference in the degree of morbidity. As accurate baseline numbers for doctors and trainees within the regions covered by the MedNet service over the study period are not available, a measurement of the representativeness of our sample with regard to gender can not be made. However, the absence of differences in degree of morbidity by gender does not confirm previous work, which has found increased morbidity in female doctors, most often measured by the GHQ [1,2].

The largest group of doctors to attend were aged 30-39 years, who were specialist registrars coming to the end of their training and thus looking for consultant posts, there were also a significant number of newly-appointed consultants. This data lends support to the view that one of the most stressful times for registered doctors is the transition from trainee to full responsibility as either a consultant or principal general practitioner

Data from self-report measures show that $63 \%$ of the entire cohort of doctors seen had significant morbidity as measured by the CORE-OM and $85.1 \%$ reached caseness on the BSI, however only $9 \%$ scored above adult outpatient psychiatric norms indicating that only a small number were severely psychiatrically distressed. In terms of suicidal risk, $42 \%$ were considered to be at risk by the therapists. The BSI was able to reflect the level of general morbidity in this population, but was limited in being able to identify the specific population of suicidal doctors as identified clinically by the CORE-A.

A survey of newly qualified doctors in Norway found that $14 \%$ of doctors had seriously thought about or planned suicide in the preceding year [21]. In our sample, 11 had attempted suicide, eight in the preceding 12 months. This is well above the annual rate for attempted suicide in the general population, which is $0.5 \%$ per annum [11], with the doctors attending the service showing at least a 13-fold difference compared to the general population. Closer scrutiny of the higher risk group showed that only two were severely distressed according to the BSI. Three had negligible time off sick. The lack of a clear pattern in this special group, some working whilst suicidal, illustrates the difficulty in identifying such problems unless the individual is motivated to seek help.

A total of $28 \%$ of the cohort had been on sick leave for more than 4 working weeks ( $\leq 21$ days) in the preceding year, the majority with depression. This adds further evidence to the finding that the doctors who attend are extensively distressed with a small sub-group who are at significant personal risk; clients with a history of attempted suicide having a significantly higher risk of sui- 
cide [22]. The fact that $50 \%$ took little or no leave in the preceding 12 months suggests that MedNet clients represent both ends of the spectrum of severity.

The fact that $72 \%$ were encouraged to attend by medical colleagues indicates that their problems had become visible enough to engender concern. The vast majority had completed their postgraduate exams, indicating that academic performance was not compromised. Clinical performance in the study was judged by self-report and the clinical judgement derived from consultation with the doctors. No direct objective evidence was available. The adverse effect of stress and poor health on performance is well documented [23]. More than 75\% of this cohort reported that they had work-related issues that had arisen within the preceding year; however the majority did not have serious performance problems (there is no rating for impairment for those off sick, which may skew the results to underreporting performance problems). Up to 33\% reached the criteria for burnout and there were high levels of emotional exhaustion as measured by the MBI. This data in conjunction with our clinical impression shows that in general clinical performance is relatively preserved, even though the individual doctor is significantly distressed and that despite serious distress, clients' jobs had not yet been jeopardised. Many of them, despite high levels of emotional exhaustion, had maintained medium to high levels of personal accomplishment. This would support the view that doctors with such difficulties put all their available energy into maintaining their professional identity by working through their illness [24], with their exhaustion manifesting itself when off duty.

Approximately $25 \%$ of the doctors were on sick leave more than one working month; this represents a group that merits further study. The main finding that emerged from this study about this group is that although there is a trend to higher levels of morbidity, concerns about work and associated significant degrees of burnout were the most important determinants of sick leave over 20 days duration.

\section{Conclusion}

In summary, this specialist service was successful in enabling doctors with considerable distress both personally and in the workplace, a small number being at significant risk, to receive help. Although the majority of the doctors in the study had made occasional contact with their GP in the preceding year, our clinical impression is that they had not engaged in more intensive help before making contact with our services. We suggest that many of these doctors would not have done so if a confidential self-referral service was not available and that the findings lend weight that such services do achieve earlier engagement in a significant proportion of doctors attending, enhancing the possibility of 'nipping problems in the bud' both personally and professionally.

\section{Competing interests}

The author(s) declare that they have no competing interests.

\section{Authors' contributions}

$\mathrm{RH}$ wrote the protocol and obtained funding for this audit supporting IR as research fellow. AIG acted as the investigator for the later stages of the study following RH's retirement. SRG conducted secondary data analysis for this paper and prepared the present manuscript with AIG. All authors contributed to and approved the final manuscript.

\section{Acknowledgements}

We thank all participating doctors for their involvement in this project. We are grateful to Mrs Chrystalla Loizou for her help in data collection and administration of the research project. We would also like to thank Professor Elisabeth Paice, Dean Director, London Deanery for her support both for the clinical service and for the research project and her encouragement and advice. This audit and the service itself were funded by the London Deanery.

\section{References}

I. Borrill CS, Wall TD, West MA, Hardy GE, Shapiro DA, Carter AJ, Golya DA, Haynes CE: Mental Health of the Workforce in NHS Trusts. Phase I: Final Report University of Sheffield and University of Leeds; 1996.

2. Bergman B, Ahmad F, Steward DE: Physician health, stress and gender at a university hospital, differential analyses in outcome according to gender. J Psychosomatic Res 2003, 54: I7I- I 78.

3. Krakowski AJ: Stress and the practice of medicine II; stressors, stresses and strains. Psychother Psychosomatic 1982, 38: I I-23.

4. Linzer M, Gerrity M, Douglas JA, McMurray JE, Williams ES, Konrad TR: Physician stress: results from the physician work life study. Stress Health 2002, 18:37-42.

5. McManus IC, Winder BC, Gordon D: Are UK doctors particularly stressed? Lancet 1999, 354:1358-1359.

6. Taylor C, Graham J, Potts HWW, Richards MA, Ramirez AJ: Changes in mental health of UK hospital consultants since the mid-1 990s. Psychother Psychosomatic 2005, 366:742-744.

7. Edwards N, Kornachi MJ, Silversin J: Unhappy doctors: what are the causes and what can be done? BMJ 2002, 324:835-838.

8. Shanafelt TD, Bradley KA, Wipf JE, Back AL: Burnout and self reported patient care in an internal medicine residency program. Ann Int Med 2002, 136:358-367.

9. McManus IC, Winder BC, Gordon D: The casual links between stress and burnout in a longitudinal study of UK doctors. Lancet 2002, 359:2089-2090.

10. Hawton K, Clements A, Sakarovitch C, Simkin S, Deeks J): Suicide in doctors: a study of risk according to gender, seniority and specialty in medical practitioners in England and Wales, 1979-1995. J Epidem Comm Health 200I, 55:296-30I.

II. Tyssen R, Vaglum P, Gronvold NT, Ekeberg O: Suicidal ideation among medical students and young physicians: a nationwide and prospective study of prevalence and predictors. J Affect Disord 200I, 64:69-79.

12. Frank E, Dingle AD: Self-reported depression and suicide attempts among US woman physicians. Am J Psych 1999, 156:1887-1999.

13. Schneck SA: The patient-physician relationship. JAMA 1998, 280:2039-2042.

14. Firth-Cozens J: A perspective on stress and depression. In Understanding Doctors' Performance Edited by: Cox J, King J, Hutchinson A, McAvoy P. Oxford: Radcliffe Publishing; 2006:22-37. 
15. McKevitte C, Morgan M: Illness doesn't belong to us. J Royal Soc Med 1997, 90:49|-495.

16. Center C, Davis M, Detre T, Ford DE, Hansbrought W, Hendin H, Laszlo J, Litts DA, Mann J, Mansky PA, Michels R, Miles SH, Proujansky $\mathrm{R}$, Reynolds CF, Silverman MM: Confronting depression and suicide in physicians: a consensus statement. JAMA 2003, 289:3|6|-3|66.

17. CORE System Trust: CORE System Tools Portfolio. Memo 493 Leeds, Psychological Therapies Research Centre; 2005.

18. Evans CE, Mellor-Clark J, Margison F: Clinical outcomes in routine evaluations: the CORE Outcome Measure (CORE-OM). J Ment Health 2000, 9:247-255.

19. Derogatis LR: BSI Brief Symptom Inventory - Administration, Scoring and Procedures Manual 3rd edition. Minneapolis, MN: National Computer Services; 1993.

20. Maslach C, Jackson SE: The measurement of experienced burnout. J Occ Behav 198I, 2:99-113.

21. Meltzer H, Lader D, Corbin T, Singleton N, Jenkins R, Brugha T: Nonfatal Suicidal Behaviour Among Adults Aged 16 to 74 in Great Britain London, The Stationery Office; 2000.

22. Owens D, Horrocks J, House A: Fatal and non-fatal repetition of self-harm. Brit J Psych 2002, 181:193-199.

23. Firth-Cozens J: Interventions to improve physicians' well-being and patient care. Soc Sci Med 200I, 52:215-222.

24. McKevitt C, Morgan M, Dundas R, Holland WW: Sickness absence and 'working through' illness: a comparison of two professional groups. J Pub Health Med 1997, 19:29.

\section{Pre-publication history}

The pre-publication history for this paper can be accessed here:

http://www.biomedcentral.com/1741-7015/5/26/prepub

Publish with Bio Med Central and every scientist can read your work free of charge

"BioMed Central will be the most significant development for disseminating the results of biomedical research in our lifetime. "

Sir Paul Nurse, Cancer Research UK

Your research papers will be:

- available free of charge to the entire biomedical community

- peer reviewed and published immediately upon acceptance

- cited in PubMed and archived on PubMed Central

- yours - you keep the copyright

Submit your manuscript here:

http://www.biomedcentral.com/info/publishing_adv.asp 